\title{
Teacher-student eye contact during scaffolding collaborative mathematical problem-solving
}

\author{
Eeva Haataja, Miika Toivanen, Anu Laine and Markku S. Hannula \\ University of Helsinki, Finland
}

\begin{abstract}
Teacher's gaze communicates consciously and unconsciously her pedagogical priorities to the students. By creating and responding to eye contact initiatives, people can communicate both status and affection. This research explores the frequency of teacher-student eye contacts and their connection to teachers' scaffolding intentions. The data consisted of mobile gaze tracking recordings of two teachers and stationary classroom videos during three collaborative mathematical problem-solving lessons. The quantitative analysis showed that most of the teacher gazes on student faces did not lead to dyadic eye contacts and those gazes that did, occurred often during affective and cognitive scaffolding. These results offer us novel and important insight in the nonverbal part of scaffolding interaction.
\end{abstract}

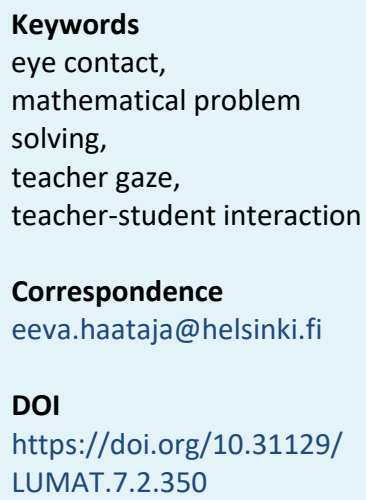

\section{Introduction}

Nonverbal interaction plays an important role in the classroom. In teacher-student nonverbal interaction, students learn by following teacher's gaze and through eye contact with the teacher (Csibra \& Gergely, 2009; Shteynberg, 2015). The teacher directs her gaze towards targets that are of high priority to her and, by this direction, conveys these priorities to the students during instruction (Shteynberg, 2015). In the classroom, students are the most important attentional priority for the teachers (McIntyre, 2016). Especially their solution papers, faces, and hands are the most relevant gaze targets for the teacher during scaffolding collaborative mathematical problem-solving process (Haataja, Garcia Moreno-Esteva, Toivanen, \& Hannula, 2018).

Dyadic (two-sided) eye contacts between two persons are one component in nonverbal communication and they can convey both immediacy and authority (Mehrabian, 1972). People tend to focus on other people's eyes to interpret their affects (Itier, 2015) and the information from the environment (Shteynberg, 2018). However, situational social structures and a person's intentions affect her willingness to form a dyadic eye contact with others, which highlights the importance of real-life contexts in data collection (Tatler \& Land, 2015). Our data investigates this phenomenon from the teacher's viewpoint by combining classroom videos with mobile gaze tracking recordings. The unconscious nature of gaze direction (Tatler, 
Kirtley, Macdonald, Mitchell, \& Savage, 2014) and the significance of the eye contact in human interaction and student learning underline the importance of examining this phenomenon and its relations to teachers' pedagogical intentions. In this study, we investigate the means of teacher-student eye contact interaction during collaborative mathematical problem solving. The results are reflected from the viewpoint of the teachers' scaffolding intentions.

\section{Scaffolding interaction}

The teacher's actions in supporting students' learning in problem-solving process towards the goals of their zone of proximal development are called scaffolding (Wood, Bruner, \& Gail, 1976). Scaffolding is a contingent interactive process between the teacher and the students (Van de Pol, Volman, \& Beishuizen, 2010). In scaffolding, the teacher facilitates students' learning by offering them guidance that she tailors for the student's needs in a certain phase of the problem-solving process (Hermkes, Mach, \& Minnameier, 2018; Van de Pol et al., 2010). The teacher's intentions for scaffolding can be divided into three categories: cognitive, affective, and metacognitive (Van de Pol et al., 2010).

With cognitive scaffolding, the teacher structures and adapts the problem task to better correspond with students' competences (Van de Pol et al., 2010). To provide help of right quality and quantity, the teacher has to analyze carefully how students construct and try to solve the task (Hermkes et al., 2018). Elaborate introduction as well as tailored, activating questions on the strategies and contents of the problem advance students' cognitive learning during the process (Kojo, Laine, \& Näveri, 2018).

The affective intention means teacher's acts to promote students' motivation and prevent frustration during the problem-solving process (Van de Pol et al., 2010). Problem solving is a teaching method that often includes multiple emotions (Pesonen \& Hannula, 2014). Positive emotions enhance mathematical learning while negative emotions affect vice versa (Pekrun, Lichtenfeld, Marsh, Murayama, \& Goetz, 2017).

Metacognitive scaffolding refers to guiding students' learning process by directing their attention and interaction towards relevant objects (Van de Pol et al., 2010). In collaborative problem solving, also the metacognitive processes are of social nature. Especially while solving demanding problem tasks, the successful learning process requires metacognitive negotiation between the members of the collaboration group (Iiskala, Vauras, Lehtinen, \& Salonen, 2011). 


\section{Teacher-student eye contact}

Shared attention conveys cognitive information and intensifies affective experiences such as emotional states (Shteynberg, 2018). Behaviors to produce the experiences of interpersonal closeness in other people are called nonverbal immediacy (Andersen, Andersen, \& Jensen, 1979). Nonverbal immediacy behaviors, such as eye contact (Andersen et al., 1979; Mehrabian, 1972), are interdependent with teachers' communication skills (Bainbridge Frymier \& Houser, 2000). Teacher's nonverbal immediacy increases the students' experiences of cognitive and affective learning and engagement in learning and studying mathematics (McCluskey, Dwyer, \& Sherrod, 2017).

Eye contact transfers experiences of affiliation, positive attitude, and warmth towards the other person (Mehrabian, 1972). With eye contact, the teacher communicates to students that they are in the locus of her attention and the interaction or information implicates them (Adams, Nelson, \& Purring, 2013; McIntyre, Mainhard, \& Klassen, 2017). Teacher's gaze towards the students, while listening to them, increases their experience of close interpersonal relationship with the teacher (McIntyre et al., 2017). Teachers also see that eye contact with students is in connection to good teacher-student contact. The quality of the contact between the teacher and students form one link between teacher behavior and student learning (Korthagen, Attema-Noordewier, \& Zwart, 2014).

Direct face-targeted gaze also includes information on person's social status and authority (Brey \& Shutts, 2015; Mehrabian, 1972). With direct gaze, the teacher can address the role of the student in the instruction and the meaningfulness of the learning contents (Böckler, van der Wel, \& Welsh, 2014). During teacher-centered instruction, students tend to relate teacher's eye contact with communication of authority and dominance (McIntyre, 2016). Mere immediacy cannot produce learning without clarity and relevance of the instruction (Mottet et al., 2008). Direct eye contact can increase the effectiveness of teaching, as the students interpret the nonverbal communication to form conceptions of the teacher and the instruction (Babad, 2009).

Doherty-Sneddon and Phelps (2007) have investigated teachers' interpretations of students' eye contact initiatives and found out that, during working on challenging tasks, teachers connected students' averted gaze with deep thinking. Thus, teachers interpreted students' avoidance of eye contact to correlate with contributing in the 
zone of proximal development and did not want to interrupt that cognitive process. During teachers' speech, student's eye contact initiative was understood as a sign of motivation and understanding (Doherty-Sneddon \& Phelps, 2007).

Questionnaire and video research have shown the importance of teacher-student eye contact as a part of classroom communication from the perspective of student experiences on motivation (Zeki, 2009) and teacher immediacy (Babad, 2009) during instruction. However, the educational field lacks first-hand evidence on the occurrence and significance of this part of the nonverbal classroom communication. Our previous case study (Haataja et al., in press) found a relation between teacher's visual attention and the intentions of scaffolding on student collaboration. The teacher focused on students' faces more while scaffolding affective aspects than during cognitive or metacognitive scaffolding (Haataja et al., in press). The current study zooms into the characteristics and role of teachers' face targeted gazes in scaffolding interaction during collaborative mathematics lessons.

\section{Research questions}

To explore the relation between teacher-student eye contact and teachers' scaffolding intentions (cognitive, affective, and metacognitive), our research questions were:

1. "In what ways do teachers interact with students in terms of eye contact during collaborative mathematical problem solving?"

2. "How do the frequency and durations of teacher-student eye contacts differ across the teachers' scaffolding intentions?"

\section{Methods}

We collected the data for this research during three mathematics lessons in three Finnish lower secondary schools. We chose three qualified mathematics teachers with different levels of expertise. The data collection with teachers 1 (middle-career) and 2 (novice) took place in the spring of 2017 and with the teacher 3 (experienced) in the winter of 2018. The participating classes were situated in a large Southern Finnish city. The classes included ninth-grade students, 15-16 years of age. We received the permissions for the data collections from the school principals. The teachers and the classes volunteered for this research, students' parents were informed, and all students filled a written consent form. As an acknowledgement of their contribution, 
the classes received small donations to their school trip account and the target students, and the teachers received gift cards.

The mathematics teacher 1 was 39 years old and had 14 years of teaching experience. To secure her anonymity, we call her with pseudonym Joanne. Joanne had seven boys and twelve girls in her class. They were seated in pairs and, during the collaborative phase of the lesson, formed five collaboration groups of three to five students. The teacher 2 was 30 years old with three years of experience in teaching mathematics. This teacher is called with pseudonym Fred. Fred's class included eleven boys and eight girls. The students sat in pairs and worked in five collaboration groups of two to four students. One girl in Fred's class did not participate in the task of the lesson and had personal tasks. The teacher 3 was 56 years old and we call her Lily. She possessed 31 years of teaching experience and had six boys and three girls in her class. Lily's students were sitting in collaboration groups of four, three, and two members.

With all three classes, three stationary video cameras and several microphones recorded the actions and verbal communication during the lessons. Additionally, in every class four target students and the teacher wore mobile gaze tracking devices that recorded their visual attention during the lesson. The gaze tracking devices were selfmade and consisted of two eye cameras, a scene camera, and simple electronics attached in plastic goggles (Toivanen, Lukander, \& Puolamäki, 2017). A dedicated software computed the gaze point in the scene camera with average accuracy of approximately 1.5 degrees of visual angle.

To investigate the scaffolding interaction, we examined the collaborative problemsolving phases in the middle of the observed mathematics lessons and excluded the instructive phase in the beginning and presentation phase in the end of the lessons from the analysis. The collaborative phases lasted about 18 minutes in Joanne's, 16 minutes in Fred's, and 17 minutes in Lily's class. The task of the lessons was a geometry problem (Figure 1). The goal was to find the optimal way to connect four imaginary cities, located at the vertices of a square, with an electrical cable. To solve the problem, students were allowed to use paper, pencils, rulers, and calculators. In Lily's class, they also used laptop computers with Geogebra software. 


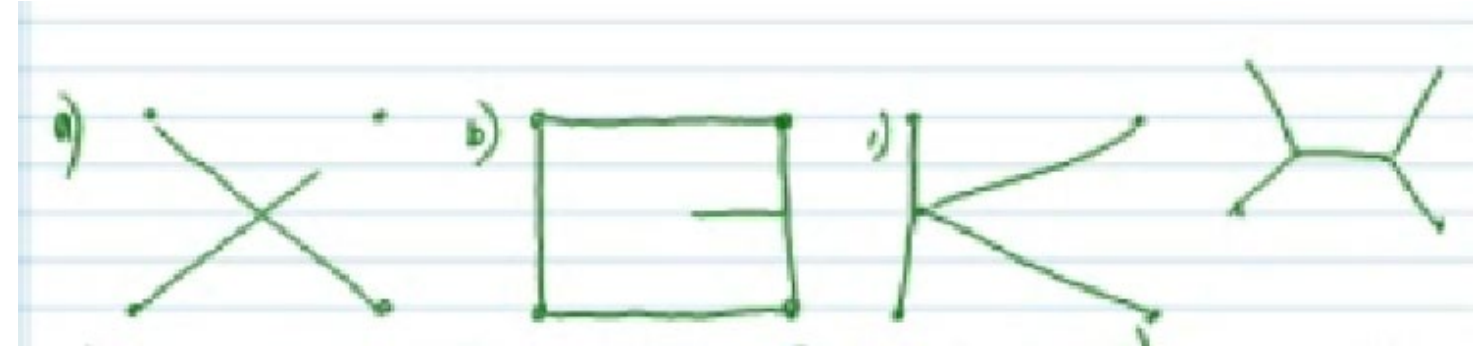

Figure 1. Four solution drafts to the problem task, the optimal solution furthest on the right. A capture from a Smartpen recording on a student in Joanne's class.

The researchers instructed the teachers to guide the students during the problemsolving process by supporting them and posing questions on the process but not giving hints on the optimal solution. During the session, all teachers roamed in the classroom and offered scaffolding to one group at a time. Joanne gave more wholeclass instructions during the collaborative phase than Fred or Lily. Additionally, Joanne and Lily instructed their students to move in the class to observe the solutions of other collaboration groups.

To analyze the data, we coded teacher's gazes with ELAN software with a dwell time as a coding unit. Dwell time is a single gaze dwell on a specific target (e.g. face) that consists of one or more fixations (Holmqvist et al., 2011). Each dwell that was at least 80 milliseconds long was coded according to its target. As this analysis is done from the teachers' viewpoint, the gaze duration was defined as the dwell time of teacher gaze at a student's face. We separated one-sided student-face targeted dwells from those with dyadic eye contact and divided the dyadic eye contact gazes according to the initiative part of the gaze. Thus, we had three gaze categories: (1) a teacher gaze on student face, (2) a teacher-started dyadic eye contact, and (3) a student-started dyadic eye contact.

The scaffolding intentions were coded according to the classroom video and classified into five categories. Three scaffolding categories arose from the theory of Van de Pol et al. (2010): (1) cognitive, (2) affective, and (3) metacognitive scaffolding. These three intentions of scaffolding were defined by analyzing the verbal teacherstudent interaction. During cognitive scaffolding, the teachers helped the students with the mathematical contents of the task, during affective scaffolding, they encouraged and motivated them, and during metacognitive scaffolding, the teachers directed the students' attention towards the task. To cover also the moments of scaffolding that did not include verbal interaction we added two more categories. These categories were (4) monitoring (teacher watching collaboration to get an idea 
of what stage the group is in the problem-solving process) and (5) fading (final scanning of the group before moving on to another group).

After the coding, we conducted quantitative analyses with IBM SPSS software. To form an overview of the research topic, we analyzed the teachers' gaze behavior during the collaborative problem-solving sessions with descriptive quantitative analysis. After that, the relation between the occurrence of the eye contact categories and teachers' momentary scaffolding intentions were analyzed with crosstabs and Pearson's Chi-square test using the Bonferroni adjusted pairwise comparisons with expected cell counts. To investigate the amounts of visual attention invested in the teacher-student eye contacts, the main effects of gaze durations for teacher persons, scaffolding intentions, and eye contact types were analyzed with two-way analysis of variance. The gaze durations were transformed into logarithmic scale to improve the validity of the ANOVA. However, in the results section we present them in the original, linear form for the clarity and readability of the report.

\section{Results}

The distribution of visual attention of Joanne, Fred, and Lily towards student-related targets were quite similar to each other. However, the total count of student-targeted gazes was twice as high in Joanne's $(N=1498)$ and Fred's $(N=1547)$ classes than in Lily's $(N=712)$ class. During Lily's lesson, some technical issues with student laptops stole her time, and she had to focus on non-pedagogical targets, such as the researchers and her own computer.

We start the results by presenting the overall distribution of teachers' gazes at student-related targets during collaborative mathematical problem-solving session (Figure 2). These gazes were recorded while students solved the problem task in collaboration groups and the teachers walked around the classrooms to scaffold the learning process. 


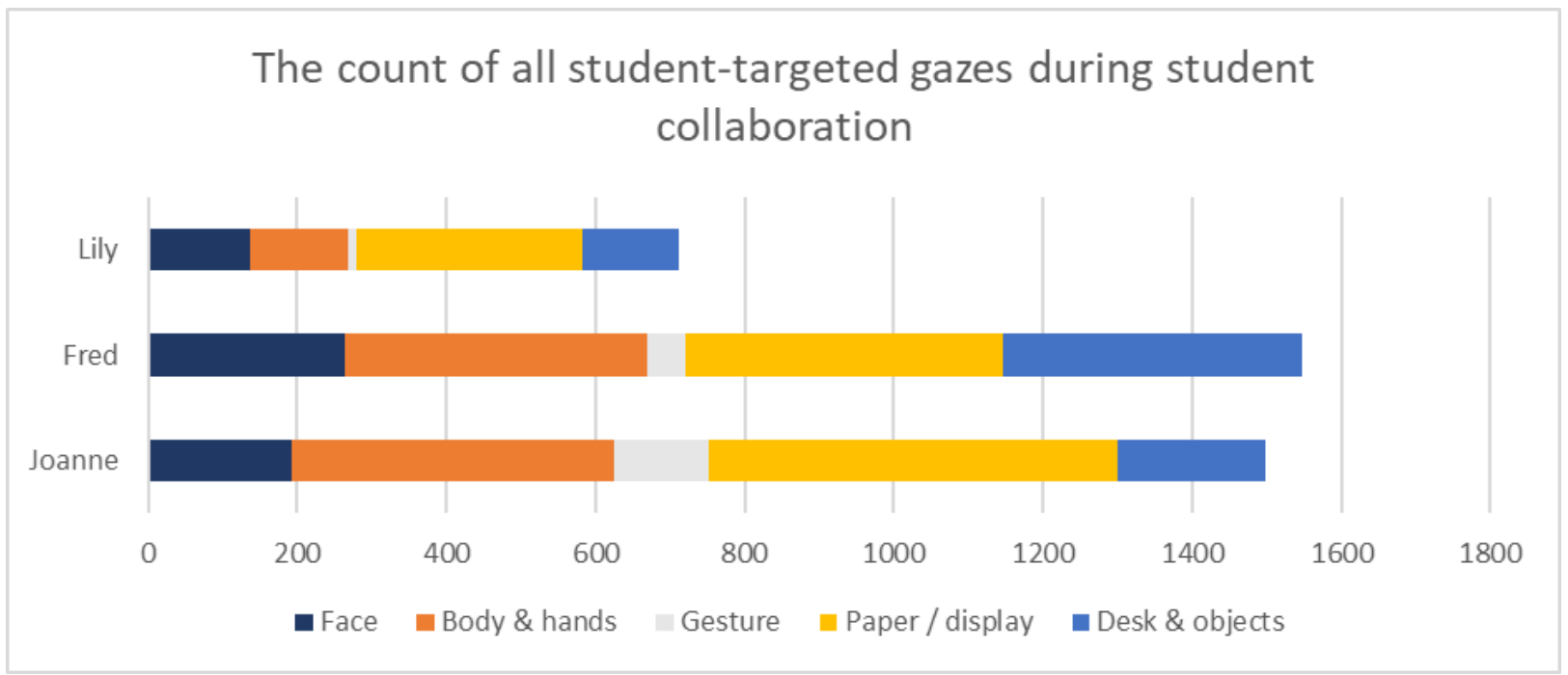

Figure 2. The count of teacher gazes towards student-related targets during collaborative phases of three separate mathematical problem-solving lessons. Fred's data has been previously presented in Haataja et al., in press.

While scaffolding the collaborative problem-solving session, the teachers focused most on students' solution papers to receive information on their cognitive process. Additionally, all the teachers payed attention to students' bodies and hands as well as desks and other objects while they monitored activities and working of the students. However, paper-targeted gazes were longer than body or desk targeted, and in the comparison of total dwell time, paper-targeted gazes formed the majority of teacher's visual attention. The teachers also directed attention to students' gestures when the students pointed at their solutions while explaining them.

In this study, we focus on teachers' student-face targeted gazes. Face-targeted gaze dwells covered $13 \%$ of Joanne's visual attention by both count of gazes and the total dwell time. With Fred, students' faces captured $17 \%$ of the gaze count and $18 \%$ of total dwell time. With both these teachers, the mean durations of face-targeted gazes were close to the mean durations of all gazes. In Lily's class, the face-targeted gazes were shorter on average. By count, they cover $19 \%$ of Lily's gazes but by total dwell time only $9 \%$ of Lily's visual attention.

The teachers gazed at their students' faces frequently throughout the collaborative phase but the majority of teacher gazes at student faces did not include dyadic eye contact. Joanne gazed at her students' faces 191 times during the collaborative learning phase. The total dwell time of these gazes was 89 seconds and mean duration 0.46 seconds $(S D=.632)$. In $40 \%$ of Joanne's face-targeted gazes, a dyadic eye contact was formed between her and a student. Fred directed 264 gazes towards 
students' faces lasting 143 seconds in total and 0.54 seconds on average ( $S D=.633$ ). Of these gazes, $30 \%$ included a dyadic eye contact. Lily's 137 face-targeted gazes lasted 59 seconds altogether, with the average of 0.43 seconds $(S D=.546)$. The proportion of dyadic eye contacts was $23 \%$ of all Lily's gazes on student faces.

Figure 3 presents those gazes that included a dyadic eye contact between a teacher and a student. The gazes are categorized according to the initiative part of starting the contact. The distribution between teacher-started and student-started dyadic eye contacts was quite similar between the teachers.

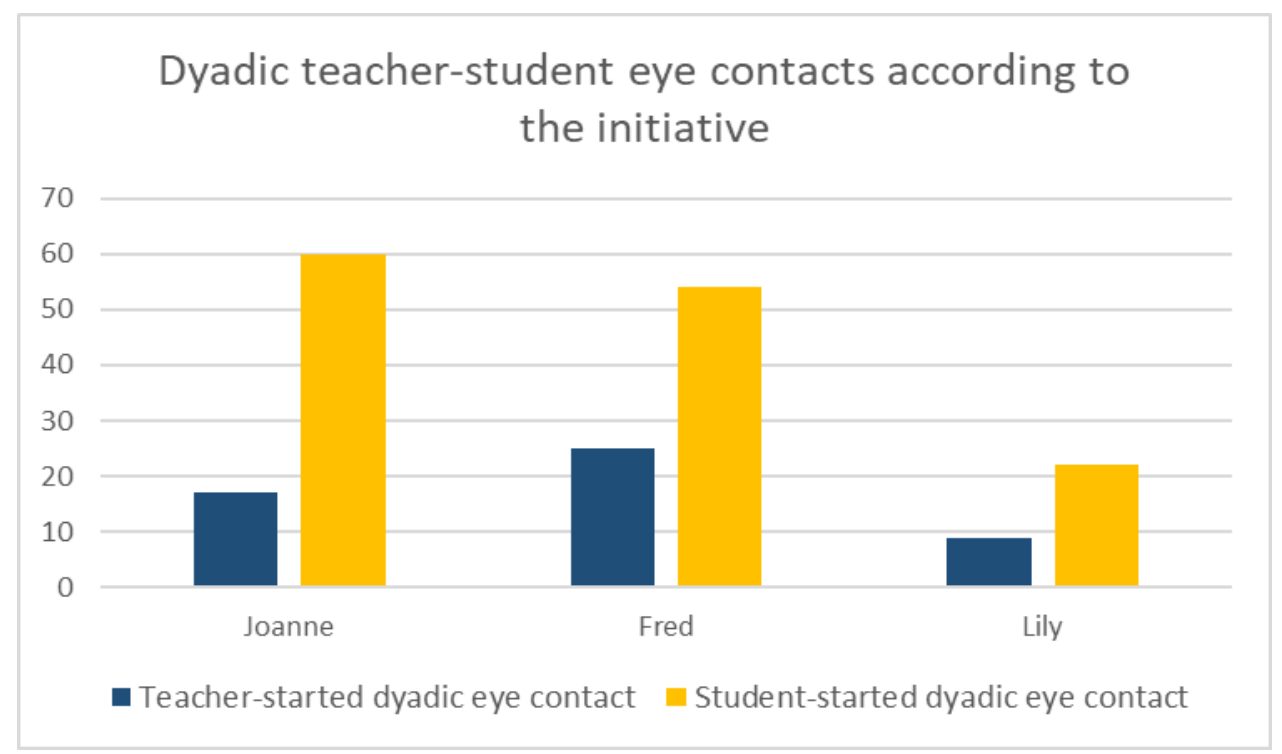

Figure 3. The count of dyadic teacher-student eye contacts according to the initiative part, three teachers compared.

Students started the eye contacts in $78 \%$ of the cases in Joanne's, $68 \%$ in Fred's, and $71 \%$ in Lily's class. Joanne had a dyadic eye contact with a student 77 times, of which 60 were started by a student's initiative. After Joanne's response to a student's cue of shared attention, Joanne ended the eye contact more often $(n=38)$ than the student did. Eye contact gazes started by the teacher occurred less often. Joanne started $22 \%$ of the dyadic eye contacts by looking the student in the face. Only three times Joanne continued looking at a student who had ended the eye contact that was started by Joanne.

In Fred's lesson, the distribution of initiatives of eye contact were relatively similar with Joanne. Fred had 79 eye contact gazes with students during the session. The most common type of eye contact was student first gazing Fred's face, Fred responding for a moment and then focusing to some other target $(n=25)$. In comparison to Joanne 
and Lily, Fred started dyadic eye contact gazes most often (32\%). With Fred, the students also ended teacher-started dyadic eye contacts more often $(n=9)$ than with the other teachers.

During the analyzed phase of Lily's lesson, 31 dyadic eye contact gazes were formed between her and her students. Similarly, to other two teachers, also with Lily, the students started, and she ended the dyadic eye contacts most often $(n=16)$. The nine (29\%) teacher-started dyadic eye contacts included only one student-ended eye contact and eight eye contacts that Lily ended.

To summarize, the dyadic eye contacts between the teachers and students were most often started by a student and ended by a teacher. The opposite category (teacher started, student ended) was the least frequent category. This can be interpreted to result from the general interactional roles of the teachers and the students in the classrooms, where the teacher is in a central position and in a leading role during interaction with the students. The following chapter examines, whether the teachers' momentary pedagogical intentions affected the occurrence of these gaze categories.

\section{Teacher-student eye contacts during scaffolding interventions}

The teachers tended to stop by one group at a time to receive information on their proceeding (monitoring and fading) and offer them cognitive (mathematical), affective (motivational and emotional), and metacognitive (attentional and procedural) scaffolding. During cognitive scaffolding, the teachers asked questions about the solutions the students had drawn on their papers and displays and gave the procedural advice on how to continue by drawing more solutions and comparing them by calculating or measuring the lengths of the lines. Affective scaffolding included encouraging and supporting the students when they were frustrated or bored. Scaffolding was coded as metacognitive, when the teachers asked the students to maintain or direct their attention towards the collaboration and share thoughts and talk about the problem task.

To explore the role of dyadic eye contacts in scaffolding interaction, we compared the occurrence of eye contacts with scaffolding intention categories using Pearson Chi-square test. This analysis showed significant differences in counts of eye contact categories between scaffolding intention groups $\left(X^{2}(8,379)=33.47, p<.001\right)$. The results of pairwise post hoc tests are presented in Table 1. The comparison of 
proportions revealed significant differences in the count of eye contacts during monitoring, cognitive scaffolding, and affective scaffolding.

Table 1. Eye contact categories (columns) during the scaffolding intentions (rows). The table shows the counts, the expected counts, and the percentages of each subcategory. The subsets of Eye contact categories with different subscript letters $(a, b)$ differ significantly from each other in count versus expected count ratio at the $p<.05$ level.

\begin{tabular}{|c|c|c|c|c|c|}
\hline \multirow{2}{*}{\multicolumn{2}{|c|}{ Scaffolding intention }} & \multicolumn{3}{|c|}{ Eye contact } & \multirow{3}{*}{$\begin{array}{l}\text { Total } \\
\mathbf{5 7}\end{array}$} \\
\hline & & \multirow{2}{*}{$\begin{array}{l}\text { One-sided } \\
48_{\mathrm{a}}\end{array}$} & \multirow{2}{*}{$\begin{array}{l}\text { Teacher-started } \\
\mathbf{1}_{\mathbf{a} \cdot \mathbf{b}}\end{array}$} & \multirow{2}{*}{$\begin{array}{l}\text { Student-started } \\
\mathbf{8}_{\mathbf{b}}\end{array}$} & \\
\hline Monitoring & Count & & & & \\
\hline & Expected Count & 37.3 & 4.7 & 15.0 & 57 \\
\hline & $\%$ within group & $84.2 \%$ & $1.8 \%$ & $14.0 \%$ & $100 \%$ \\
\hline \multirow[t]{3}{*}{ Cognitive } & Count & $54 a$ & $10_{a \cdot b}$ & $41_{b}$ & 105 \\
\hline & Expected Count & 68.7 & 8.6 & 27.7 & 105 \\
\hline & $\%$ within group & $51.4 \%$ & $9.5 \%$ & $39.0 \%$ & $100 \%$ \\
\hline \multirow[t]{3}{*}{ Affective } & Count & $51_{a}$ & $14_{b}$ & $20_{a}$ & 85 \\
\hline & Expected Count & 55.6 & 7.0 & 22.4 & 85 \\
\hline & $\%$ within group & $60.0 \%$ & $16.5 \%$ & $23.5 \%$ & $100 \%$ \\
\hline \multirow[t]{3}{*}{ Metacognitive } & Count & $71_{a}$ & $5 a$ & $28 a$ & 104 \\
\hline & Expected Count & 68.1 & 8.5 & 27.4 & 104 \\
\hline & $\%$ within group & $68.3 \%$ & $4.8 \%$ & $26.9 \%$ & $100 \%$ \\
\hline \multirow[t]{6}{*}{ Fading } & Count & $24 a$ & $\mathbf{1}_{\mathrm{a}}$ & $3 a$ & 28 \\
\hline & Expected Count & 18.3 & 2.3 & 7.4 & 28 \\
\hline & $\%$ within group & $85.7 \%$ & $3.6 \%$ & $10.7 \%$ & $100 \%$ \\
\hline & Count & 248 & 31 & 100 & 379 \\
\hline & Expected Count & 248 & 31 & 100 & 379 \\
\hline & $\%$ & $65.4 \%$ & $8.2 \%$ & $26.4 \%$ & $100 \%$ \\
\hline
\end{tabular}

During monitoring and fading phases of teachers' scaffolding, dyadic eye contacts were less frequent and one-sided teacher gazes at student faces more frequent than the expected count assumed. This difference was statistically significant within the category of monitoring. Instead of dyadic scaffolding interaction, monitoring and fading reflected teachers' control on students as the teachers followed and scanned the work of small-groups before and after scaffolding interventions. Typically, the students did not disrupt their actions while gazed by their teachers. This led us to the interpretation that ninth-graders are already accustomed to being under teachers' visual attention and do not respond to teachers' face-targeted gazes without interactional purpose.

On the contrary, dyadic teacher- and student-started eye contacts were relatively frequent during cognitive and affective scaffolding. In cognitive scaffolding, the count 
of student-started dyadic eye contacts was significantly higher than the count of onesided teacher gazes at student faces in relation to the expected count. During the cognitive scaffolding, teachers focused more on students' solution papers and less on student faces than during other intentions of scaffolding. However, the students tended to look at teachers' faces while listening to them. After making sense of students' written solutions, teachers often responded to students' initiatives of dyadic eye contacts to concentrate on students' questions and explanations, to explain the mathematical contents, or to ensure mutual understanding of the situation.

During affective scaffolding, the count of teacher-started dyadic eye contacts differed significantly from the other categories. During these phases, the teachers made more initiatives for teacher-started dyadic eye contact. The intention of the teachers in affective scaffolding directed their gaze to collect information on students' emotional stages. The interaction also included support and encouragement that probably created the feeling of immediacy and enhanced student responses to teachers' eye contact initiatives. The teacher-student interaction seemed to be more equal during affective than metacognitive or cognitive scaffolding. For instance, the students joked and argued with their teachers. In these situations, the dyadic eye contact seemed to form naturally between the participants of interaction.

In moments of metacognitive scaffolding, the teacher gazes at student faces were often one-sided. When dyadic eye contacts occurred, they were usually studentstarted. In metacognitive scaffolding, the teachers instructed students to collaborate and focus on the problem task and were more interested in their actions than their facial expressions. Students probably looked at them to understand better the instructions that often-concerned changing position or the patterns of peer interaction. In these moments, the teachers also often called the students by their names, which captured the students' attention.

To conclude, the one-sided teacher gazes at student faces were common during teachers' monitoring, fading, and metacognitive scaffolding. During these categories of interaction, the students were under teachers' supervision and not as active in the nonverbal communication as during cognitive and affective scaffolding. When scaffolding cognitive and affective aspects of the problem solving, the teachers and students were in reciprocal interaction, and created dyadic eye contacts to reach shared understanding on the momentary scaffolding intentions. However, also the durations of the gazes include information on the attentive choices of the participants, and these will be explored in the following. 


\section{Gaze durations}

To form a broader picture on the amounts of teacher-student eye contact interaction, the durations of the gazes were also analyzed. The influences of three independent variables (teacher, scaffolding intention, eye contact) on the durations of teachers' face-targeted gazes were analyzed with two-way ANOVA. No significant interaction effects were found with the analysis. Additionally, the main effect of the teacher person was not significant $(F(2,370)=2.09, p=.125)$, and thus we are able to examine the results of the three teachers together.

The main effect for eye contact category yielded an $F$ ratio of $F(2,370)=18.83, p$ $<.001$, indicating significant differences between all three categories of eye contact: one-sided teacher gaze at student face $(M=409.69 \mathrm{~ms}, S D=361.09)$, teacher-started dyadic eye contacts $(M=1001.84 \mathrm{~ms}, S D=1256.12)$, and student-started dyadic eye contacts $(M=707.24 \mathrm{~ms}, S D=811.49)$. The pairwise Bonferroni adjusted post hoc comparison showed that teacher-started dyadic eye contacts were significantly longer than student-started dyadic eye contacts $(p=.001)$ or one-sided teacher gazes at student faces $(p<.001)$. Gazes with a student-started dyadic eye contact were also significantly longer than those without dyadic eye contact $(p=.019)$.

The longest face-targeted gazes occurred during cognitive and affective scaffolding. The main effect for scaffolding intention yielded an $\mathrm{F}$ ratio of $F(4,370)=$ 8.45, $p<$.001. According to Bonferroni adjusted pairwise post hoc tests, the gazes during cognitive scaffolding $(M=773.83 \mathrm{~ms}, S D=1048.48)$ were significantly longer than gazes during monitoring $(M=282.25 \mathrm{~ms}, S D=222.25, p<.001)$, fading $(M=$ $334.36 \mathrm{~ms}, S D=264.71, p=.007)$, and metacognitive scaffolding $(M=425.47 \mathrm{~ms}, S D$ $=401.80, p=.03)$. Also, face-targeted gazes during affective scaffolding $(M=737.20$ $\mathrm{ms}, S D=786.81)$ were longer than those during monitoring $(p<.001)$ and fading $(p$ $=.04$ ) with statistical significance. Metacognitive scaffolding, monitoring, and fading did not differ significantly from each other.

The longest gazes occurred during cognitive and affective scaffolding when the teachers started the dyadic eye contacts. The student-started dyadic eye contacts were also relatively long. The one-sided teacher-gazes at student faces were generally short, as were the gazes during teachers' monitoring the student groups. To compare the gaze durations in the five scaffolding categories, we conducted a two-way analysis of variance. 


\section{Discussion and conclusion}

This report examined eye contacts, one aspect of teacher-student nonverbal communication, in momentary scaffolding interaction. We compared the occurrence of teacher gazes at student faces and dyadic teacher-student eye contacts between the categories of teachers' scaffolding intentions. On all three collaborative problemsolving lessons, the dyadic eye contact gazes between teachers and students were less frequent than one-sided teacher gazes at student faces.

The one-sided teacher gazes were the most common during teacher monitoring and fading from the student group, that is, during moments with no verbal teacherstudent interaction. Students seemed to be used to being under teachers' visual observation while working on their task. In these moments, teachers seemed to convey their pedagogical expectations and status in the classroom with mere gaze. From interactional perspective, students' aversion of gaze can be interpreted as both a sign of noticed teacher control (Böckler et al., 2014; Mehrabian, 1972) and a signal of well-proceeding problem-solving process (Doherty-Sneddon \& Phelps, 2007). Beneficial instruction is a combination of immediacy and control (Mottet et al., 2008), and in these moments the teachers seemed to communicate the latter.

According to our research, a typical dyadic eye contact between a teacher and a student started from a student's initiative and ended by the teacher. The role of the teacher as the authority and leader in the classroom directs students' visual attention towards them (McIntyre, 2016). Additionally, students have the natural tendency to follow the instructing adult's attention to learn relevant contents (Csibra \& Gergely, 2009). On one hand, the teachers may have distinct goals for the communication with students. For instance, during cognitive scaffolding, the teacher focuses mainly on students' solution papers (Haataja et al., in press). On the other hand, the teachers are responsible for scaffolding all the students, and thus may unconsciously shorten the gazes to distribute their attention evenly among the students.

The present study indicates that regardless of teachers' intentions of scaffolding, the students tend to start eye contacts with them. Probably the eye contacts ease concentrating on teacher's speech in a noisy class environment by looking at her face or try to predict teacher's emotional stage and demands from her eyes. However, this may lead to not noticing teacher's instructive gestures as she explains the task and solution procedures. In addition to sufficient scaffolding through the teacher's activating questions (Kojo et al., 2018), the students might benefit from explicit 
guidance on attention direction during scaffolding interaction. In future, it would be interesting to investigate these moments from students' perspective to interpret their understanding of teacher-student eye contacts and noticing of teacher gestures.

Teacher-started dyadic eye contacts were the least frequent gaze category. However, they consisted of the longest gazes in the analysis. In the comparison between scaffolding intentions, the longest gazes occurred during cognitive and affective scaffolding. This indicates that teachers also seek for information from dyadic eye contacts, especially during affective scaffolding. These gazes may strengthen the message of affective scaffolding by increasing the nonverbal immediacy between the teacher and the student (Korthagen et al., 2014; McIntyre et al., 2017).

This research is the first phase of our analysis on teacher-student eye contact. The small sample size can be seen as its limitation. However, our participant teachers represent different levels of teaching experience, genders, and school neighborhoods. These results on Joanne, Lily, and Fred's face-targeted gazes are in line with our previous case study on the distribution of the visual attention of Fred (Haataja et al., in press; Haataja et al., 2018). Additionally, the similarities of the participants' gaze behaviors despite the differences in their teaching experience, taught classes, and the course of the data collection lessons suggest that there are certain general patterns in teacher-student eye contact communication. This encourages us to continue in this path as well as with general theories of nonverbal interaction. In future, comparisons between a larger number of teachers and students from different backgrounds would be fascinating.

The reliability of the analysis is also important to be reflected. One researcher conducted the coding in an interaction with the rest of the research group. Some eye contacts were difficult to interpret from to teacher gaze data. Two researchers interpreted the unclear moments, and very fuzzy gazes were excluded from the analyses. Additionally, the highly accurate gaze data and the triangulation of data collection increase the reliability of the analysis. The stationary video recording and gaze data complemented each other during unclear moments.

This data collection method offers data on sensory perceptions that are partly unconscious for the participant. Thus, we have asked for an ethical review of the University of Helsinki Ethical Review Board in the Humanities and Social and Behavioral Sciences. We noticed that despite the inconveniences of the research 
setting, the participating teachers and students were interested in our method of data collection and excited about the mathematics lesson that included problem solving and collaboration.

To summarize the conclusion, students follow teachers' gaze throughout the lesson and teachers seem to use eye contact for at least two purposes. On one hand, they create immediacy by making initiatives for dyadic eye contacts to support affective scaffolding. On the other hand, they respond to students' initiatives during cognitive scaffolding to enhance the interaction. These both pedagogical goals alternate throughout collaborative learning, such as mathematical problem solving. In practice, teachers would benefit from understanding this phenomenon as they plan problem-solving lessons. With explicitly directing students' visual attention towards targets that are relevant for learning in a certain situation of scaffolding interaction, they may both foster success in solving the task and enhance the deeper learning on problem-solving procedures. In the future, we wish to explore these interactional processes and to form a more exhaustive conception on the teacher-student nonverbal interaction by analyzing multiple gaze data from these sessions.

\section{Acknowledgements}

This research is a part of the MathTrack project that is funded by the Academy of Finland (grant 297856). We thank our participant teachers and students as well as Mrs. Jessica Salminen-Saari, Mr. Visajaani Salonen, and Dr. Enrique Garcia MorenoEsteva for their contribution in the data collection.

\section{References}

Adams, R. B. Jr., Nelson, A. J., \& Purring, K. (2013). Eye behavior. In J. A. Hall \& M. L. Knapp (Eds.), Nonverbal communication (pp. 229-262). New York, NY: de Gryuter Berlin.

Andersen, J. F., Andersen, P. A., \& Jensen, A. D. (1979). The measurement of nonverbal immediacy. Journal of Applied Communication Research, 7(2), 153-180. doi:10.1080/00909887909365204

Babad, E. (2009). Teaching and nonverbal behavior in the classroom. In L. J. Saha \& A. G. Dworkin (Eds.) International Handbook of Research on Teachers and Teaching (vol. 21, part 2), pp. 817-828. New York, NY: Springer.

Bainbridge Frymier, A., \& Houser, M. L. (2000). The teacher-student relationship as an interpersonal relationship. Communication Education, 49(3), 207-219. doi:10.1080/03634520009379209 
Böckler, A., van der Wel, R P, \& Welsh, T. N. (2014). Catching eyes: Effects of social and nonsocial cues on attention capture. Psychological Science, 25(3), 720-727. doi:10.1177/0956797613516147

Brey, E., \& Shutts, K. (2015). Children use nonverbal cues to make inferences about social power. Child Development, 86(1), 276-286. doi:10.1111/cdev.12334

Csibra, G., \& Gergely, G. (2009). Natural pedagogy. Trends in Cognitive Sciences, 13(4), 148-153. doi: 10.1016/j.tics.2009.01.005

Doherty-Sneddon, G., Phelps, F. G. (2007). Teachers' Responses to Children's Eye Gaze. Educational Psychology, 27(1), 93-109. doi: 10.1080/01443410601061488

Haataja, E., Garcia Moreno-Esteva, E., Salonen, V., Laine, A., Toivanen, M., \& Hannula, M. S. (in press). Teacher's visual attention when scaffolding collaborative mathematical problem solving. Teaching and Teacher Education. doi: 10.1016/j.tate.2019.102877.

Haataja, E., Garcia Moreno-Esteva, E., Toivanen, M., \& Hannula, M. S. (2018). Teacher's gaze behavior when scaffolding peer interaction and mathematical thinking during collaborative problem-solving activity. In E. Bergqvist, M. Österholm, C. Granberg, \& L. Sumpter (Eds.), Proceedings of the 42nd Conference of the International Group for the Psychology of Mathematics Education (Vol. 2) (pp. 475-482). Umeå, Sweden: PME.

Hermkes, R., Mach, H., \& Minnameier, G. (2018). Interaction-based coding of scaffolding processes. Learning and Instruction, 54, 147-155. doi: 10.1016/j.learninstruc.2017.09.003

Holmqvist, K., Nyström, M., Andersson, R., Dewhurst, R., Jarodzka, H., \& Van de Weijer, J. (2011). Eye tracking: A comprehensive guide to methods and measures. Oxford: Oxford University.

Iiskala, T., Vauras, M., Lehtinen, E., \& Salonen, P. (2011). Socially shared metacognition of dyads of pupils in collaborative mathematical problem-solving processes. Learning and Instruction, 21(3), 379-393. doi: 10.1016/j.learninstruc.2010.05.002.

Itier, R. J. (2015). Attention to eyes in face perception. In: J. Fawcett, E. Risko, \& A. Kingstone (Eds.), The handbook of attention (pp. 369-388). Cambridge, MA: MIT Press.

Kojo, A., Laine, A., \& Näveri, L. (2018). How did you solve it? - Teachers' approaches to guiding mathematics problem solving. LUMAT: International Journal on Math, Science and Technology Education, 6(1), 22-40. doi:10.31129/LUMAT.6.1.294

Korthagen, F., Attema-Noordewier, S., \& Zwart, R. (2014). Teacher-student contact: Exploring a basic but complicated concept. Teaching and Teacher Education, 40, 22-32. doi: 10.1016/j.tate.2014.01.006

McCluskey, R., Dwyer, J., \& Sherrod, S. (2017). Teacher immediacy and learning mathematics: Effects on students with divergent mathematical aptitudes. Investigations in Mathematics Learning, 9(4), 157-170. doi:10.1080/19477503.2016.1245047

McIntyre, N. A. (2016). Teach at first sight: Expert teacher gaze across two cultural settings (Doctoral dissertation). University of York, York.

McIntyre, N. A., Mainhard, M. T., \& Klassen, R. M. (2017). Are you looking to teach? Cultural, temporal and dynamic insights into expert teacher gaze. Learning and Instruction, 49, 4153. doi: 10.1016/j.learninstruc.2016.12.005

Mehrabian, A. (1972). Nonverbal communication. Chicago, IL: Aldine.

Mottet, T. P., Garza, R., Beebe, S. A., Houser, M. L., Jurrells, S., \& Furler, L. (2008). Instructional communication predictors of ninth-grade students' affective learning in math and science. Communication Education, 57(3), 333-355. doi:10.1080/03634520801989950

Pekrun, R., Lichtenfeld, S., Marsh, H. W., Murayama, K., \& Goetz, T. (2017). Achievement emotions and academic performance: Longitudinal models of reciprocal effects. Child Development, 88(5), pp. 1653-1670. doi: 10.1111/cdev.12704 
Pesonen, J. A., \& Hannula, M. S. (2014). Analyzing students' emotional states during problem solving using automatic emotion recognition software and screen recordings. Proceedings of PME 38 and PME-NA: Conference of the International Group for the Psychology of Mathematics Education and the 36th Conference of the North American Chapter of the Psychology of Mathematics Education, 36(4), 417-424.

Shteynberg, G. (2015). Shared attention. Perspectives on Psychological Science, 10(5), 579-590. doi:10.1177/1745691615589104

Shteynberg, G. (2018). A collective perspective: Shared attention and the mind. Current Opinion in Psychology, 23. doi: 10.1016/j.copsyc.2017.12.007

Tatler, B., Kirtley, C., Macdonald R.G., Mitchell, K.M.A., \& Savage, S.W. (2014). The active eye: Perspectives on eye movement research. In M. Horsley, M. Eliot, B.A. Knight, \& R. Reilly (Eds.), Current trends in eye tracking research (pp. 3-16). Cham, Switzerland: Springer.

Tatler, B., \& Land, M. (2015). Everyday visual attention. In J. Fawsett, E. Risko, \& A. Kingstone (Eds.), The handbook of attention (pp. 391-421). Cambridge, MA: MIT Press.

Toivanen, M., Lukander, K., \& Puolamäki, K. (2017). Probabilistic approach to robust wearable gaze tracking. Journal of Eye Movement Research, 1O(4), 1-26. doi: 10.16910/jemr.10.4.2

Van de Pol, J., Volman, M., \& Beishuizen, J. (2010). Scaffolding in teacher-student interaction: a decade of research. Educational Psychology Review, 22, 271-297. doi: 10.1007/s10648010-9127-6

Wood, D., Bruner, J., \& Gail, R. (1976). The role of tutoring in problem solving. Journal of Child Psychology and Psychiatry, 17(2), 89-100. doi: 10.1111/j.1469-7610.1976.tboo381.x

Zeki, C. P. (2009). The importance of non-verbal communication in classroom management. Procedia - Social and Behavioral Sciences, 1(1), 1443-1449. doi: 10.1016/j.sbspro.2009.01.254. 